\title{
Genus Kitasatospora, taxonomic features and diversity of secondary metabolites
}

\author{
Yōko Takahashi \\ The genus Kitasatospora was proposed in 1982. Although Kitasatospora strains resemble Streptomyces strains in morphology, \\ they are clearly different in cell-wall composition, as they contain both LL- and meso-diaminopimelic acid. Aerial and submerged \\ spores contain LL-, while vegetative and submerged mycelia contain mainly meso- in their cell walls. Currently, 23 species \\ have been validly proposed. Members of the genus Kitasatospora form a tight cluster and represent a legitimate genus distinct \\ from Streptomyces on the basis of phylogenetic analysis of 16S rRNA gene sequences. A variety of biologically active \\ compounds have been found from Kitasatospora strains and structures of these compounds are extremely diverse. Genome \\ sequences of 15 strains published so far are about 7-9 $\mathrm{Mb}$ in size and contain many genes governing secondary metabolites. \\ The Journal of Antibiotics (2017) 70, 506-513; doi:10.1038/ja.2017.8; published online 15 February 2017
}

\section{INTRODUCTION}

While screening for new bioactive metabolites, an actinomycete strain KM-6054 was isolated as a producer of a nematocidal substance, setamycin. ${ }^{1}$ Unlike most actinomycetes, KM-6054 produced submerged spores with mycelia in liquid culture. At first, the two kinds of cells were wondered whether contamination or not. During taxonomic study of the strain, it was confirmed that the submerged spores were not due to contamination and originated from KM-6054 and the chemical composition of the strain was not the case with the cell wall types proposed by Lechevalier and Lechevalier. The strain was therefore not classified into any of the known genera of the order Actinomycetales. The Kitasatospora was proposed as a new genus of the order Actinomycetales on the basis of morphological characteristics and chemical composition in the cells of KM-6054 in $1982 .^{2}$ Strain KM-6054 was named as Kitasatospora setae $\mathrm{KM}-6054^{\mathrm{T}}$.

The genus Kitasatospora was transferred to the genus Streptomyces by a hybridization experiment using Streptomyces-specific $18 \mathrm{bp}$ oligonucleotide probes of $16 \mathrm{~S}$ rRNA genes in $1992 .{ }^{3}$ In 1997, ${ }^{4}$ Zhang et al. revived the genus Kitasatospora on the basis of phylogenetic analyses using 16S rRNA genes and 16S-23S rRNA gene spacers. The authors concluded that the genus Kitasatospora is a legitimate genus, distinct from Streptomyces, on the basis of phenotypic and genetic differences. Twenty three species have been validly proposed up to now.

Several novel chemicals have been discovered from Kitasatospora strains, including compounds with unique structures and interesting activities. This paper presents an overview of the taxonomic features of the genus Kitasatospora and the diversity of compounds produced by the various species in the genus.

\section{TAXONOMIC FEATURES OF THE KITASATOSPORA}

Morphological characteristics.

The ${ }^{5}$ strains of Kitasatospora grow well on both synthetic and organic agar media. The appearance of the colony is leathery. Figure 1 shows aerial mycelia (AM) and vegetative mycelia (VM) of Kitasatospora setae $\mathrm{KM}-6054^{\mathrm{T}}$, which is the type species and type strain of Kitasatospora. No fragmentation of the VM, sporangia, motile spores and sclerotia are observed. The AM produce more than 20 spores, aerial spores (AS), per chain. The morphological characteristics of KM-6054 grown on an agar medium resemble those of strains of the genus Streptomyces. ${ }^{2}$ In submerged culture, Kitasatospora strains produce submerged spores (SS) from an early stage. Scanning electron micrographs displayed in Figure 2 show morphological change in a submerged culture using yeast extract-dextrose medium of strain KM- $6054^{\mathrm{T}} .^{6}$ The images show that the SS start budding at $1 \mathrm{~h}$, only vegetative mycelia are observed at $9 \mathrm{~h}$, and SS appear at $15 \mathrm{~h}$.

Chemical compositions in cell wall and whole-cell, and taxonomic criteria of the genus Kitasatospora

One of the most important criteria of the genus Kitasatospora is the cell wall components. The cell wall hydrolysates of the Kitasatospora strains contain similar amounts of both LL-diaminopimelic acid (DAP) and meso-DAP, (one of the important keys for chemotaxonomy), as well as glycine and galactose. Whole-cell hydrolysates of the strainKM-6054 ${ }^{\mathrm{T}}$ contain galactose, while arabinose and xylose are absent. The predominant menaquinones are MK- $9\left(\mathrm{H}_{6}\right)$ and MK-9 $\left(\mathrm{H}_{8}\right)$. The phospholipid type is type PII. The acyl type of muramic acid is the acetyl type (Table 1). Kitasatospora setae KM- $6054^{\mathrm{T}}$ is the type species and strain. ${ }^{2,7}$

When the strain KM- $6054^{\mathrm{T}}$ was cultured in a liquid medium, SS and mycelia were produced in stationary phase. The relationship

Kitasato Institute for Life Sciences, Kitasato University, Minato-ku, Tokyo, Japan

Correspondence: Profesor Y Takahashi, Kitasato Institute for Life Sciences, Kitasato University, 5-9-1 Shirokane, Minato-ku, Tokyo 108-8641, Japan.

E-mail: ytakaha@lisci.kitasato-u.ac.jp

Received 13 October 2016; revised 5 January 2017; accepted 11 January 2017; published online 15 February 2017 

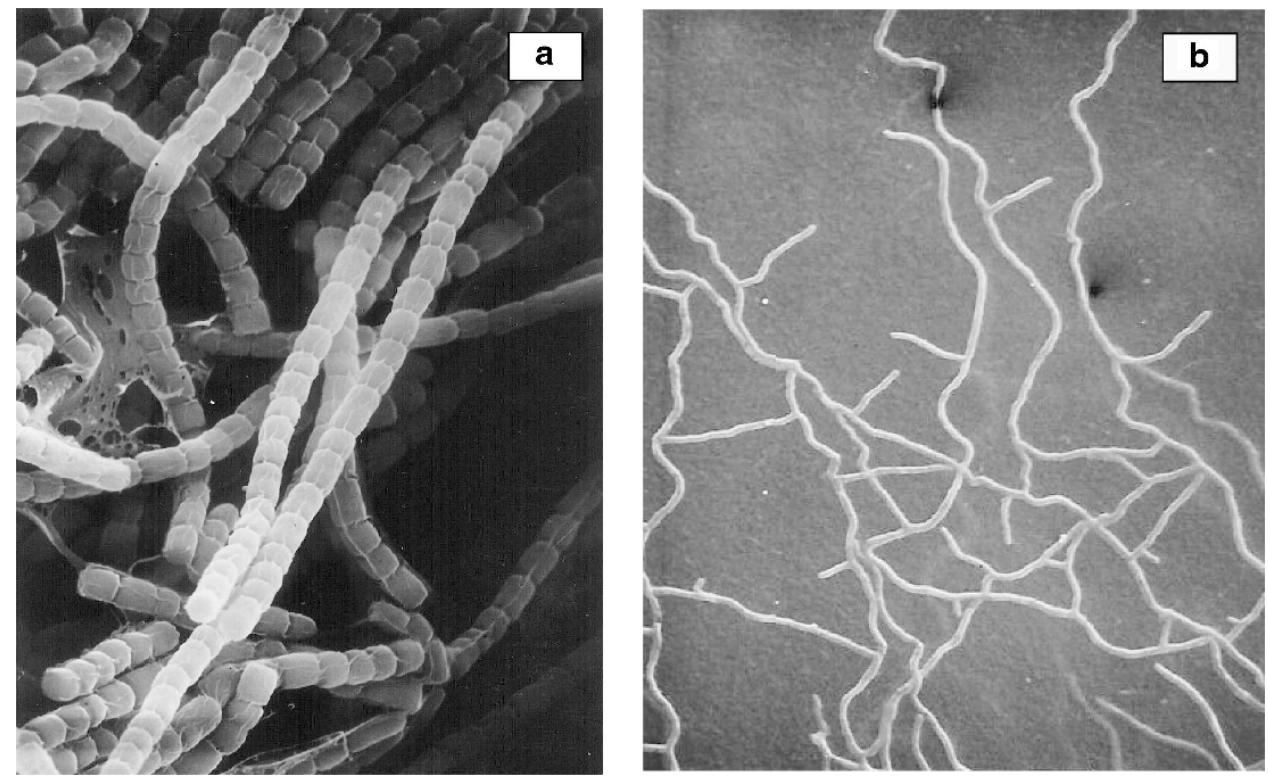

Figure 1 Aerial spore chain (a) and vegetative mycelium (b) of Kitasatospora setae KM-6054'.
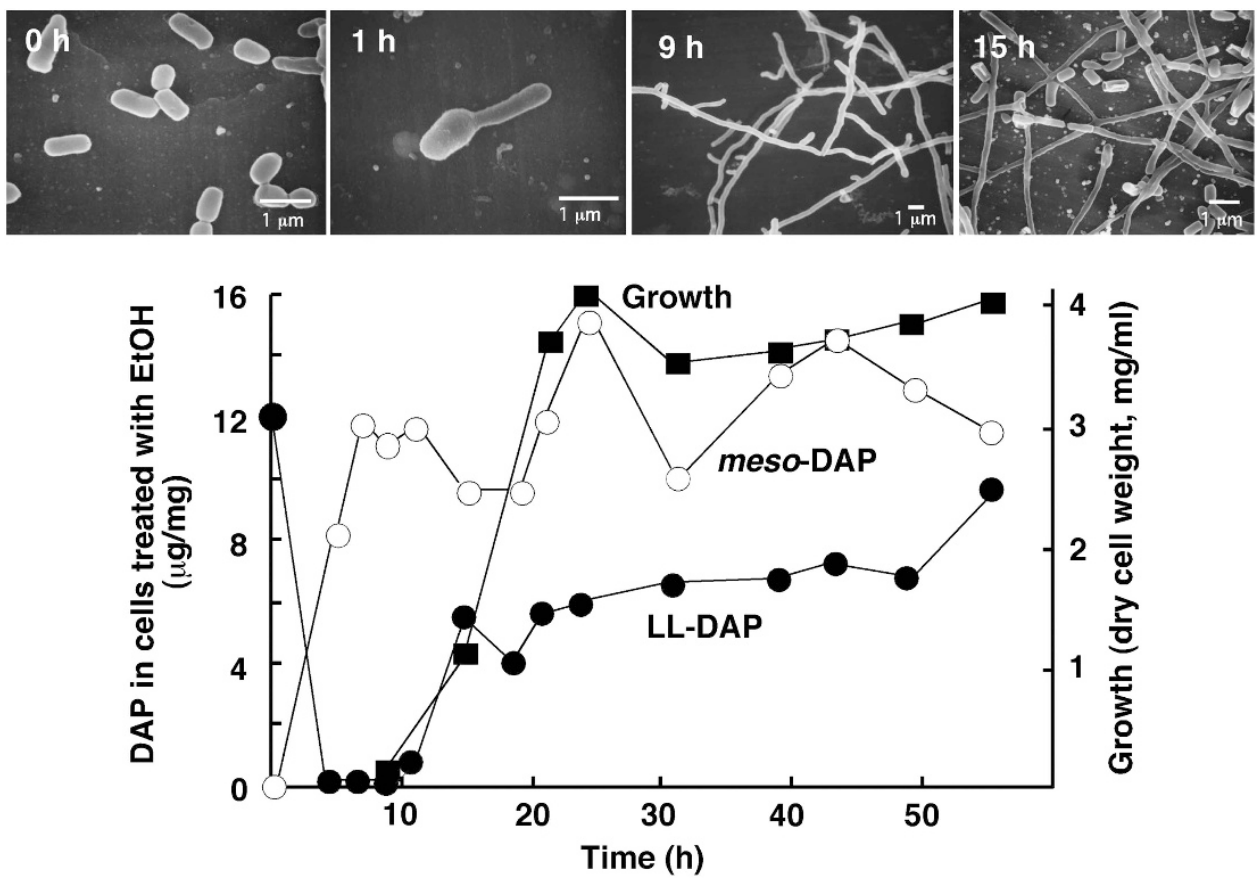

Figure 2 Time course of morphological change (scanning electron micrographs) and amounts of LL- and meso- DAP contained in the whole cells of Kitasatospora setae $\mathrm{KM}-6054^{\top}$ grown in a submerged culture.

between morphological changes and DAP isomers were investigated under synchronous liquid culture derived from only SS obtained by filtration (Figure 2). ${ }^{6,8}$ Time-dependent change show that SS inoculated begin budding after $1 \mathrm{~h}$, then continue to elongate only mycelia until $9 \mathrm{~h}$, SS appear again at $15 \mathrm{~h}$. Graph of this figure shows DAPisomer analyses using total cells. Only LL-DAP is detected at $0 \mathrm{~h}$, then amount of LL-DAP decrease, while meso-DAP content increases in association with growth of mycelia from $1 \mathrm{~h}$ to $10 \mathrm{~h}$. This means that ratio of SS decrease whereas only mycelia increase until $10 \mathrm{~h}$. SS newly differentiated from mycelia at $15 \mathrm{~h}$ begin start to budding and elongate
(Data not shown). Both LL- and meso-DAP are detected after $15 \mathrm{~h}$. Almost equal amounts of LL and meso-DAP are detected after $50 \mathrm{~h}$. These indicated that the DAP isomers clearly correlated with the cell morphology, SS contained only LL-DAP whereas mycelia contained mostly meso-DAP, hence the possibility of bacterial contamination was excluded.

On the other hand, when DAP analysis was carried out separately on AS and VM of the KM- $6054^{\mathrm{T}}$ grown on an agar medium, it was found that AS contained LL-DAP and VM contained meso-DAP. ${ }^{9}$ Further comparative study was carried out by analysis of DAP-isomers 
in morphologically-related organisms, Kitasatospora, Streptomyces, Nocardioides, Pseudonocardia and Actinomadura strains that produce long aerial spore chains. All of these reference actinomycete strains, except for $K$. setae KM- $6054^{\mathrm{T}}$, contained the same DAP isomer types in both AM/AS and VM. ${ }^{10}$ Taxonomic criteria of the genus Kitasatospora are summarized in Table 1.

Twenty three species are validly proposed at present. Figure 3 shows the phylogenetic tree based on $16 \mathrm{~S}$ rRNA gene sequences of member of the Kitasatospora. Phenotypic properties and the phylogenetic tree show that the Kitasatospora is a legitimate genus, distinguishable from Streptomyces, on the basis of phenotypic and genetic differences.

Five species, $K$. setae KM-6054 ${ }^{\mathrm{T}}, 2,11$ K. griseola $\mathrm{AM}-9660^{\mathrm{T}},{ }^{10}$

\section{Table 1 Taxonomic properties of the genus Kitasatospora}

\begin{tabular}{|c|c|}
\hline Morphology & \\
\hline Aerial spore: & Long spore chain \\
\hline Fragmentation of vegetative mycelium: & None \\
\hline Motile spore or sporangium: & None \\
\hline Submerged spore in a liquid culture: & Produced \\
\hline \multicolumn{2}{|l|}{ Chemical composition } \\
\hline Cell wall: & meso-and LL-DAP, glycine, galactose \\
\hline Whole-cell sugar: & Galactose, madurose (trace) \\
\hline Menaquinone: & MK-9 $\left(\mathrm{H}_{6}, \mathrm{H}_{8}\right)$ \\
\hline Phospholipid: & Pll type \\
\hline Acyl type: & Acetyl \\
\hline \multicolumn{2}{|l|}{ DAP isomers: } \\
\hline Aerial and submerged spore; & LL-DAP \\
\hline Vegetative and submerged mycelia; & meso-DAP \\
\hline
\end{tabular}

Abbreviation: DAP, diaminopimelic acid.
K. phosalacinea KA- $338^{\mathrm{T}},{ }^{10}$ K. cineracea SK- $3255^{\mathrm{T} 12}$ and $\mathrm{K}$. niigatensis SK-3406 ${ }^{\mathrm{T} 12}$ have been proposed by our research group. Kitasatospora strains show resistance to novobiocin (Table 2$)^{13}$ and $K$. cineracea SK-3255 ${ }^{\mathrm{T}}$ and $K$. niigatensis SK- $3406^{\mathrm{T}}$ have been isolated using agar medium containing novobiocin $\left(100 \mu \mathrm{g} \mathrm{ml}^{-1}\right)$.

\section{CHARACTERISTICS OF AERIAL AND SUBMERGED SPORES OF K. SETAE KM-6054}

Amino acid composition in cells of aerial and submerged spores. As it was not clear whether the SS could be regarded as a true spore, some characteristics of submerged spore and AS were examined. ${ }^{14}$ The SS resembled the AS in morphology, in containment of LL-DAP and in resistance to ultrasonication. In addition, transmission electron microscopy of thin sections of SS and mycelia showed that the cell walls of SS were thicker than those of mycelia (Figure 4). Analysis of amino acid compositions of the cell walls of the four kinds (AS, SS and mycelia of solid and submerged cultures) found that four amino acids, DAP, Ala, Glu and Gly, were the main components in the hydrolysates of the cell wall. The molar ratios of the amino acids in the AS and SS were similar, except for minor differences in Glu and Gly content. The amino acid compositions of mycelia of both solid and submerged cultures were essentially the same. It was found that the peptidoglycan structures of the two kinds of spores, AS and SS, were similar, but were different from those of the two kinds of mycelia (both solid and submerged cultures).

Our studies represented the first investigation of the amino acid compositions of the cell walls of the four kinds of cells derived from a single strain and which are morphologically distinguishable from each other.

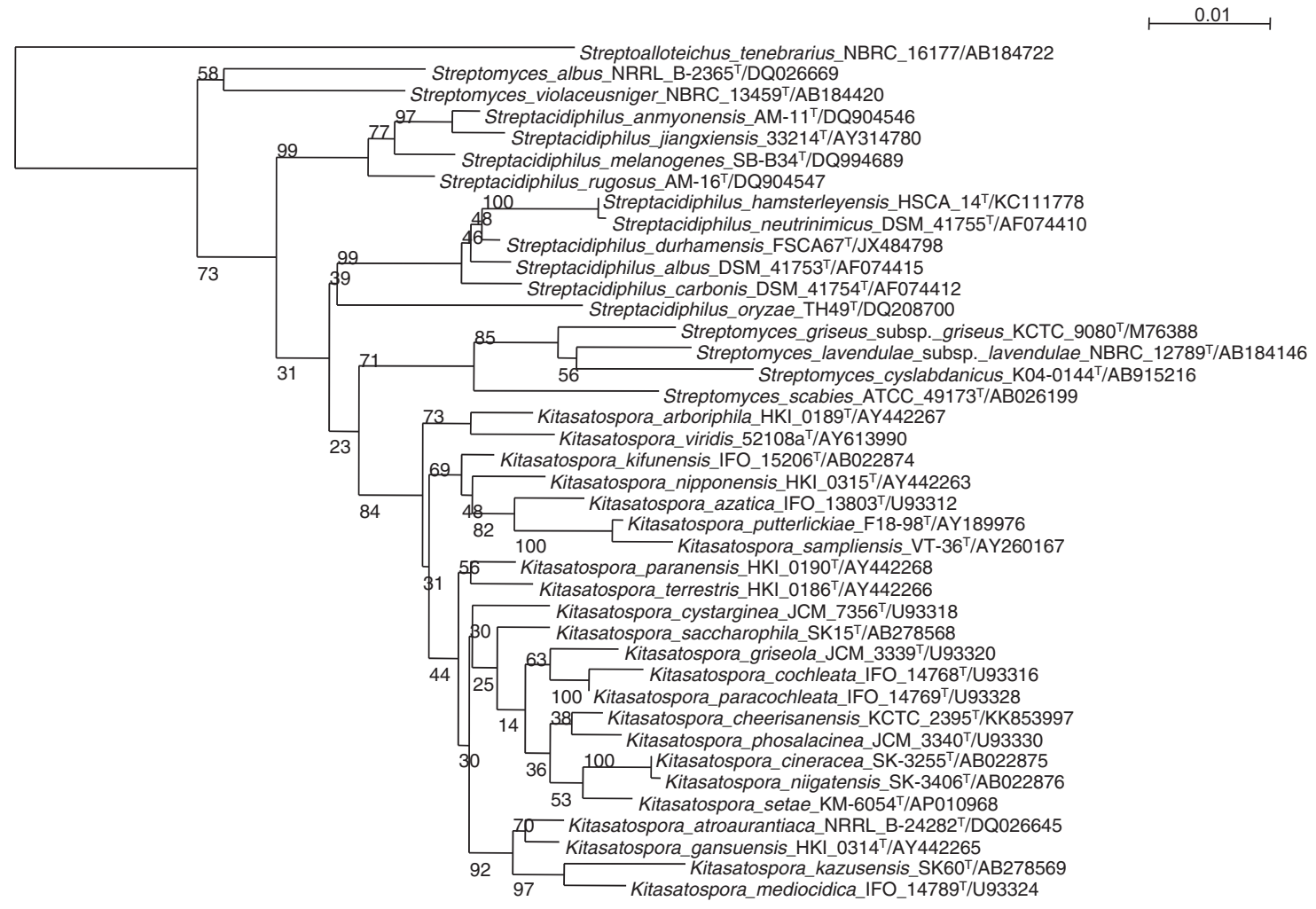

Figure 3 Phylogenetic tree based on 16S rRNA gene sequences of members of the genus Kitasatospora. 
Table 2 Antibiotic sensitivities of Kitasatospora or Streptomyces strains

\begin{tabular}{|c|c|c|c|c|c|}
\hline$M I C\left(\mu g m l^{-1}\right)$ & Ampicillin & Gentamicin & Novobiocin & Tetracycline & Tylosin \\
\hline Kitasatospora cineracea SK- $3255^{\top}$ & 3.12 & 12.5 & $>100$ & 50 & 100 \\
\hline Kitasatospora griseola OM-5023 & 6.25 & 6.25 & 100 & 25 & 25 \\
\hline Kitasatospora phosalacinea KA-338 ${ }^{\top}$ & 6.25 & 6.25 & $>100$ & 100 & 100 \\
\hline Kitasatospora niigatensis SK-3406 ${ }^{\top}$ & 3.12 & 6.25 & $>100$ & 100 & $>100$ \\
\hline Streptomyces griseus IF012875 ${ }^{\top}$ & $>100$ & 6.25 & 0.8 & 25 & $>100$ \\
\hline Streptomyces albus IF013014 ${ }^{\top}$ & 25 & 1.6 & 20 & 100 & $>100$ \\
\hline Streptomyces hygroscopicus IF013472 ${ }^{\top}$ & $<0.8$ & 1.6 & $<0.8$ & 12.5 & 0.8 \\
\hline Streptomyces tanashiensis IF012919 ' & 100 & 12.5 & 1.6 & 50 & 12.5 \\
\hline
\end{tabular}

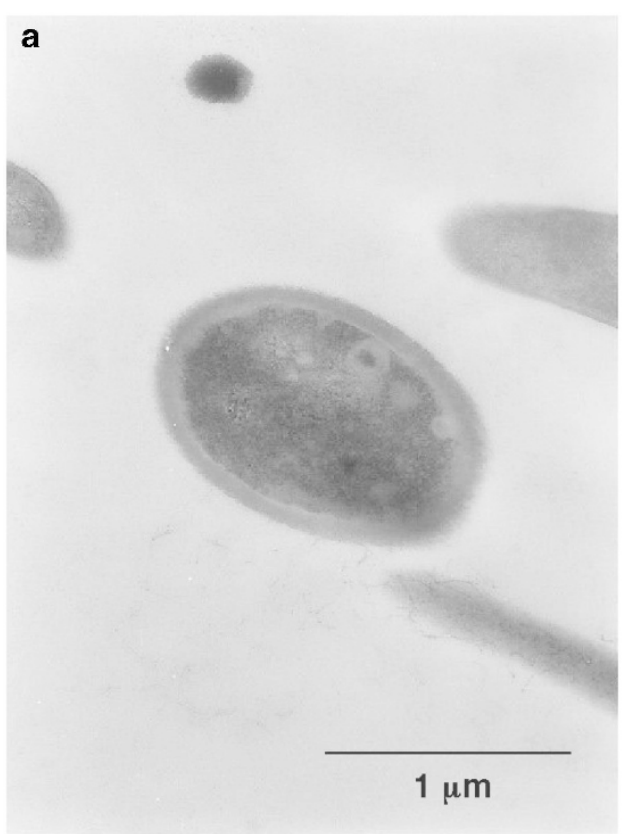

Figure 4 Transmission electron micrographs of thin sections of submerged spore (a) and mycelium (b) of Kitasatospora setae KM-6054T.

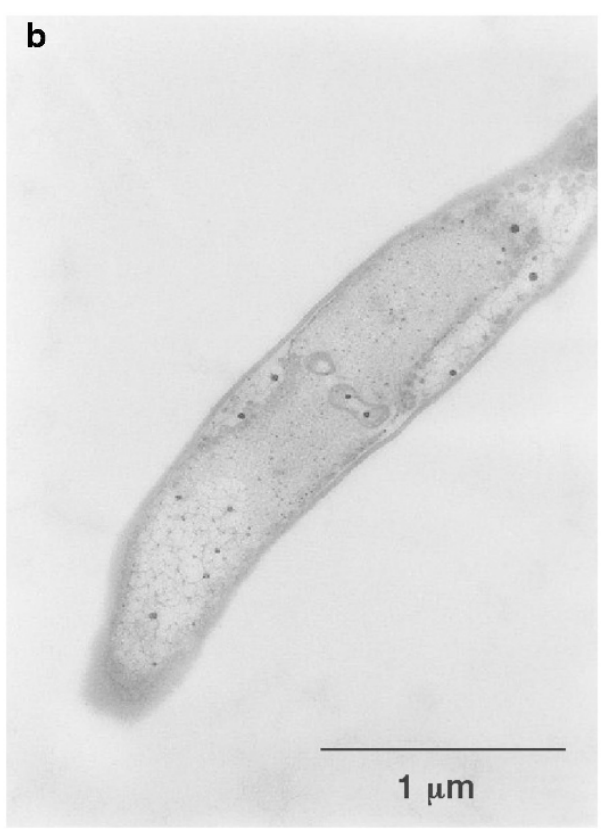

produce SS but the SS are produced by fragmentation of mycelia (Figure 5b). ${ }^{17-23}$

Feeding and shift-down experiments were carried out to identify the physiological regulation of SS formation of the strain KM- $6054^{\mathrm{T}}$ using minimum medium (MM) and casamino acid. ${ }^{24}$ In feeding experiments, the strain produced SS when casamino acids were added in MM within $4 \mathrm{~h}$ after inoculation, but not when added after $6 \mathrm{~h}$. In a nutritional shift-down experiment, SS were formed when casamino acids were removed from MM-CA after $8 \mathrm{~h}$ cultivation, but not when removed within $6 \mathrm{~h}$. SS formation may therefore require at least $8 \mathrm{~h}$ incubation under nutrient-rich conditions.

Although reports about spores formed in the submerged culture are few, cases of Streptomyces griseus, ${ }^{16,21-25}$ Streptomyces roseosporus, ${ }^{20}$ Streptomyces acrimycini, ${ }^{18}$ Streptomyces albus ${ }^{18}$ and Streptomyces venezuelae $^{19}$ have been published. Among them, Ochi et al. ${ }^{22,23}$ reported that the strain of S. griseus IFO 13189 forms SS along with a stringent response to nutritional starvation. By contrast, Ensign et al. ${ }^{25}$ reported 

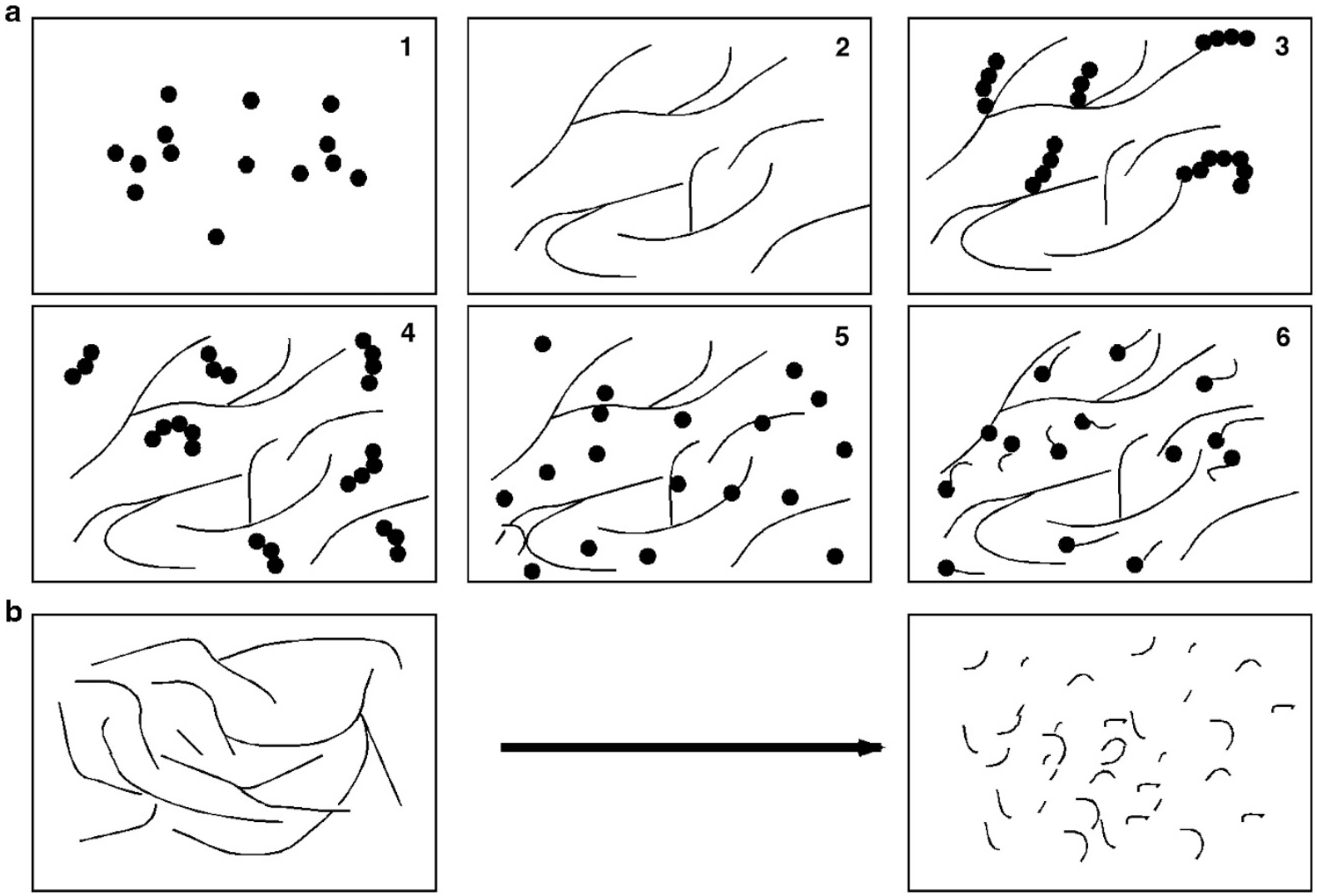

Figure 5 Differences in submerged spore formation in (a) Kitasatospora setae KM-6054 ${ }^{\top}$ and (b) Streptomyces griseus.

that the SS production of S. griseus NRRL $2682^{\mathrm{T}}$ was not controlled by nutrient limitation, but by a clocked mechanism.

It seems likely, from our experiments, that SS formation in strain $\mathrm{KM}-6054^{\mathrm{T}}$ is not regulated by nutritional starvation. As illustrated in Figure 5, the SS formation in submerged culture is apparently different from that of S. griseus. In S. griseus, SS formation occurs at a late stage of cultivation, with spores abundantly produced by random fragmentation of the mycelia. In Kitasatospora, the SS are formed in specific parts of the mycelia from an early stage and the mycelia co-exist with the SS until the late-age culture. Apparently, the tips and other specific parts of the mycelia are predestined to form the SS.

\section{DIVERSITY OF BIOLOGICAL ACTIVE COMPOUNDS PRODUCED BY KITASATOSPORA STRAINS}

\section{New compounds produced by Kitasatospora}

At least 50 bioactive compounds have been discovered so far from Kitasatospora strains. The producing strain, compound name, activities of the compounds, reported by year, are shown in Table 3.1,10,26-42 Setamycin possesses antitrichomonal and antifungal activities. Phosalacine possesses herbicidal activity. Propioxatins show enkephalinase B inhibitor. Terpentecin possesses antitumor activity, while other compounds possess a diverse range of bioactivities.

The molecular structures of the chemicals are shown in Figure 6. This figure illustrates the diversity in structures macrolide, terpene, peptide, alkaloid and polyketide- of the substances isolated from Kitasatospora strains. Caruso et al. ${ }^{38}$ reported that Kitasatospora sp. P\&U 22869, isolated from Taxus baccata, produces paclitaxel. Paclitaxel is an anti-cancer drug produced by Taxus species having been originally isolated and purified from the bark of the Pacific yew tree (Taxus brevifolia).
Table 3 and Figure 6 indicate strongly that Kitasatospora strains are highly active in producing secondary metabolites.

\section{Genome sequencing of Kitasatospora strains}

In 2010, the complete genome sequence of the setamycin (bafilomycin B1) producing strain K. setae KM-6054 ${ }^{\mathrm{T}}$ (NBRC 14216) was determined by a collaboration involving 12 organizations in Japan. ${ }^{43}$ The genome length is long (8783 $278 \mathrm{bp}$ ), as long as Streptomyces strains. Genome annotation revealed 7569 ORF, 74 tRNAs, 9 rRNA genes and 24 secondary metabolites biosynthetic gene clusters, governing production of setamycin, factumycin, spore pigment, lantiobiotic, siderophore and others. In 2012, Aroonsri et al. dicovered a novel $\beta$-carboline alkaloid, kitasetaline, from the strain $K$. setae KM- $6054^{\mathrm{T}}$ using genetic engineering. ${ }^{39}$ The kitasetaline gene was not contained in any of the 24 secondary metabolite biosynthetic gene clusters predicted in report by Ichikawa et al. ${ }^{43}$ This means that simple computational analysis based on the sequence homology has not been sufficient to find a biosynthetic genes.

The genome sequences of 15 strains are published in various database. The data shows that genome sizes are generally long (about 7-9 Mb) and contain many secondary metabolites genes. Arens et al. reported in draft genome sequencing that the setamycin (bafilomycin) producing strain $K$. griseola MF730-N6 is $7.97 \mathrm{Mb}$ in size and contains an estimated 23 secondary metabolite biosynthetic gene clusters. Although clusters for the known metabolites, hopanoids, germacradienol/geosmin, spore pigment, a valanimycin-like compound, terpentecin, satosporin, and a spore-associated protein, were identified within the genome, 15 of the 23 gene clusters governed unknown products. ${ }^{44}$ The known and, as yet unidentified, characteristics and properties of Kitasatospora strains are expected to make the 
Table 3 New compounds produced by Kitasatospora strains

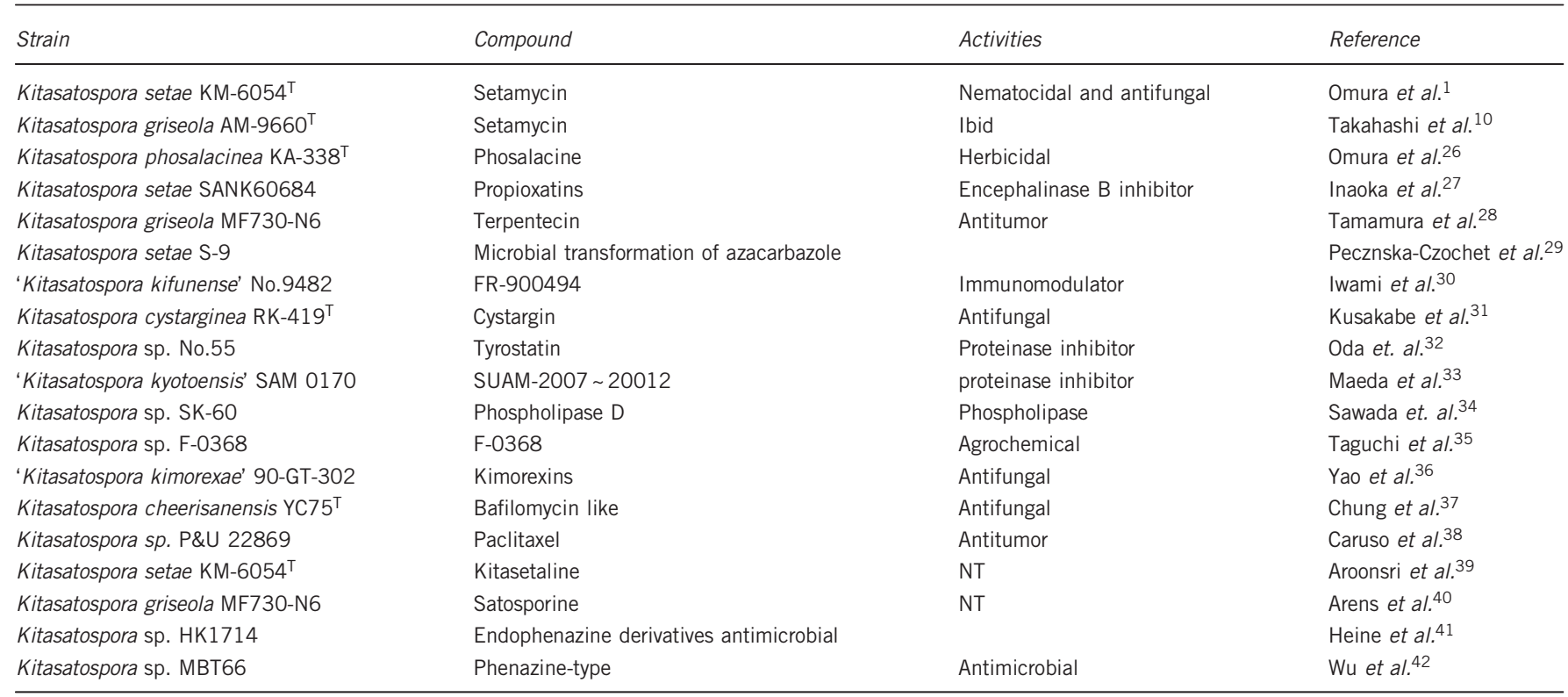

Abbreviation: NT, not reported.

Superscript T shows type strain and valid name.<smiles>CC(C)CC(=O)NC(Cc1ccc(O)cc1)C(=O)NC(CC(C)C)C(=O)NC(C=O)Cc1ccc(O)cc1</smiles>

Tyrostatin (Protease inhibitor) Kitasatospora sp.No.55<smiles>CC1=CCCC2[C@](C)(C[C@H](O)C3([C@H](O)C=O)CO3)[C@H](C)[C@@H](O)C(=O)[C@@]12C</smiles>

Terpentecin (Antitumor) K. griseola MF730-N6<smiles>C[C@]12NC(=O)C(=O)N1[C@H](CO)[C@H](O)[C@@H](O)[C@@H]2O</smiles>

Kifunensine (Immunomodulator) K. kifunensis No.9482 ${ }^{\mathrm{T}}$

Phosalacine (Herbicidal)

K. phosalaconea KA-338<smiles>CC(C)C[C@H](NC(=O)C(C)NC(=O)[C@H](N)CCP(C)(=O)O)C(=O)O</smiles>

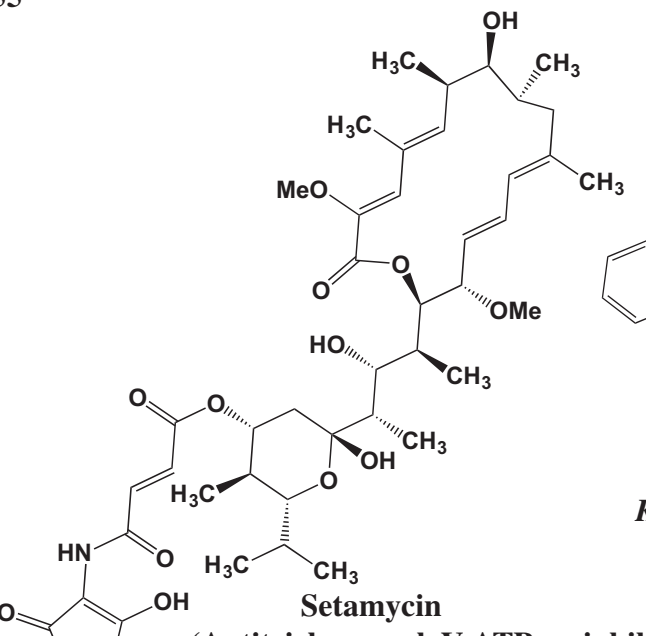<smiles>CC(=O)C(O)[C@H](NC(=O)c1ccccc1)c1ccccc1</smiles>

Pacritaxel (Antitumor)

Kitasatospora sp. P \& U 22869

Figure 6 Structures of new bioactive compounds produced by Kitasatospora strains. 
genus rich resources for future microbiological, chemical and biomedical exploration.

From chemotaxonomic characteristics, one of the most important features of the genus Kitasatospora is that the cell wall peptidoglycan contains both LL-DAP and meso-DAP. In 2014, Genevieve et al. ${ }^{45}$ discussed the differences of genes related with morphology, focusing on DAP isomers in cell wall, comparing Streptomyces and Kitasatospora strains. They reported that genes of bldB, Mbl and WhiJ associated with cell development were absent in Kitasatospora strains, these findings may lead to new insights related to the control of development processes in members of the family Streptomycetacea. Furthermore, they said that these data provided biological support phylogenetic evidence that genus Kitasatospora was a legitimate genus distinct from Streptomyces. ${ }^{45}$ Subsequently, two MurE (UDP-Nacetylmuramyl-L-alanyl-D-glutamic acid:DAP ligase) genes in the draft genome of $K$. cheerisanensis KCTC 2395 were identified by Hwang et al. in $2015 .{ }^{46}$ Furthermore, they reported that another murE gene was found from complete genome sequence of $K$. setae $\mathrm{KM}-6054^{\mathrm{T}}$. It is expected that the mechanism of peptidoglycan biosynthesis in Kitasatospora will be fully elucidated in the near future.

\section{CONCLUSION}

It can be said that the actinomycetes is a special group among prokaryotes on due to their highly-developed morphology and their ability to produce a wide range of potentially useful essential chemicals and secondary metabolites. Numerous valuable bioactive natural compounds have been discovered from actinomycete strains.

In genus level classification of the actinomycetes, morphology and chemical compositions in cells have been used effectively, together with phylogenetic analyses based on the 16S rRNA gene sequences. Though the genus Kitasatospora is similar to the genus Streptomyces in morphology, the former is clearly different from the latter in the matter of its cell wall composition because it contains LL- and mesoDAP, glycine and galactose. The DAP isomer is one of the important criteria for chemotaxonomy. Both aerial and submerged spores contain LL-DAP, while vegetative and submerged mycelia mainly meso-DAP. This was the first information regarding the DAP isomer arising from analysis of dividing spores and mycelia in submerged culture and on solid culture. In Kitasatospora, the SS are formed in specific parts of the mycelia early, the mycelia co-existing with the SS until the culture ages significantly. It appears that, in the Kitasatospora, the tips and other specific parts of the mycelia are programmed to form the SS, whereas the SS of S. griseus are formed by fragmentation of mycelia in the later stages of submerged culture.

It might be said that Kitasatospora is a genus, which was born by the development of chemotaxonomy and confirmed by gene phylogenetic classification. Twenty-three species have been published as validly name. Various biological compounds were found from secondary metabolites of Kitasatospora strains. Genome sequences of 15 strains have been opened and the data show that sizes are as long as Streptomyces strains and there are many secondary metabolite gene clusters.

During the 50 years or so of research by the Ōmura group in the Kitasato Institute or Kitasato University, some 500 new compounds have been discovered, along with 1 new family, 14 new genera and 68 new species of microorganism. About 26 compounds, including the avermectins, staurosporine, lactacystin, setamycin, nanaomycin and herbimycin, have been used widely and successfully as medicines, agricultural chemicals or biochemical reagents. These achievements have been accomplished partially due to Ōmura's strong explorer spirit and his profound determination to create a cadre of like-minded researchers who will carry on his approach and philosophy, of which I am happy, honoured and proud to be a member. The Kitasatospora, or setamycin, stand as but one firm example of the importance of his success in the natural products field and of the benefit to science and mankind when the results of the work of he and his team are applied to overcome a variety of challenges to human health and welfare.

\section{DEDICATION}

In commemoration of Distinguished Emeritus Professor, Kitasato University Satoshi Ōmura's Nobel Prize in Physiology or Medicine, I will briefly describe the story of a genus of actinomycete, Kitasatospora. Isolation, cultivation and taxonomy of microorganisms were generally inconspicuous and unregarded in the process of search for new compounds, but Professor Ōmura changed this common sense. He always emphasized the importance of microorganisms as a resource in the search for novel compounds and inspired to isolate new microorganisms. Kitasatospora was born under his this policy. I would like to celebrate Professor Ōmura's Nobel Prize in Physiology or Medicine with my sincere appreciation.

\section{CONFLICT OF INTEREST}

The author declares no conflict of interest.

\section{ACKNOWLEDGEMENTS}

I deeply thank Professor Satoshi Ōmura for his past, current and continuing encouragement and support through the years. I would also like to thank Visiting Professor Yuzuru Iwai of Kitasato University for his useful discussion and positive input in the creation of this paper. I thank Emeritus Professor Haruo Tanaka, Dr Yoshitake Tanaka and Dr Akio Seino for their useful discussion. I also thank Professor Jerald C. Ensign of Wisconsin University for his kind advice. Research on the genus Kitasatospora has been a lengthy and time-consuming endeavour and was only accomplished thanks to the contribution of many co-workers and students, too numerous to mention by name. I thank all of them for their invaluable efforts. I would also like to thank Dr Hiromi Miura for her help with genome information in this paper.

1 Ōmura, S., Otoguro, K., Nishikiori, T., Oiwa, R. \& Iwai, Y. Setamycin, a new antibiotic. J. Antibiot. 34, 1253-1256 (1981).

2 Ōmura, S., Takahashi, Y., Iwai, Y. \& Tanaka, H. Kitasatosporia, a new genus of the order Actinomycetales. J. Antibiot. 35, 1013-1019 (1982).

3 Wellington, E. M. H., Stackebrandt, E., Sanders, D., Wolstrup, J. \& Jorgensen, N. O. G. Taxonomic status of Kitasatosporia, and proposed unification with Streptomyces on the basis of phenotypic and 16S rRNA analysis and emendation of Streptomyces Waksman and Henrici 1943, 339AL. Int. J. Syst. Bacteriol. 42, 156-160 (1992).

4 Zhang, Z., Wang, Y. \& Ruan, J. A proposal to revive the genus Kitasatospora. Int. J. Syst. Bacteriol. 47, 1048-1054 (1997).

5 Takahashi, Y., Seino, A., Iwai, Y. \& Ōmura, S. Taxonomic study and morphological differentiation of an actinomycete genus. Kitasatospora. Zent. BI. Bacteriol. 289, 265-284 (1999).

6 Takahashi, Y., Iwai, Y. \& Ōmura, S. Relationship between cell morphology and the types of diaminopimelic acid in Kitasatosporia setalba. J. Gen. Appl. Microbiol. 29, 459-425 (1983).

7 Takahashi, Y. Discovery and taxonomic studies of the genus. Kitasatosporia. Actinomycetol. 3, 55-62 (1989).

8 Takahashi, Y. et al. Optical resolution of 2, 6,-diaminopimelic acid stereoisomers by high performance liquid chromatography for the chemotaxonomy of actinomycete strains. J. Gen. Appl. Microbiol. 35, 27-32 (1989).

9 Ōmura, S., Iwai, Y., Takahashi, Y., Kojima, K., Otoguro, K. \& Oiwa, R. Type of diaminopimelic acid different in aerial and vegetative mycelia of setamycin-producing actinomycete KM- 054. J. Antibiot. 34, 1633-1634 (1981).

10 Takahashi, Y. \& Iwai, S. Ōmura: two new species of the genus Kitasatosporia, Kitasatosporia phosalacinea sp. nov. and Kitasatosporia griseola sp. nov. J. Gen. Appl. Microbiol. 30, 377-387 (1984).

11 Ömura, S., Takahashi, Y., Iwai, Y. \& Tanaka, H. Revised nomenclature of Kitasatosporia setalba. Int. J. Syst. Bacteriol. 35, 221 (1985).

12 Tajima, K., Takahashi, Y., Seino, A., Iwai, Y. \& Ōmura, S. Description of two novel species of the genus Kitasatospora Ōmura et al. 1982, Kitasatospora cineracea sp. nov. 
and Kitasatospora niigatensis sp. nov. Int. J. Syst. Evol. Microbiol. 51, 1765-1771 (2001)

13 Takahashi, Y., Seki, Y., Iwai, Y. \& Ōmura, S. Taxonomic properties of five Kitasatosporia strains isolated by a new method. Kitasato Arch. Exp. Med. 61, 123-132 (1991).

14 Takahashi, Y., Kuwana, T., Iwai, Y. \& Ōmura, S. Some characteristics of aerial and submerged spores of Kitasatosporia setalba. J. Gen. Appl. Microbiol. 30, 223-229 (1984).

15 Brana, A. F., Manzanal, M. B. \& Hardisson, C. Mode of cell wall growth of Streptomyces antibioticus. FEMS Microbiol. Lett. 13, 231-235 (1982).

16 Takahashi, Y., Iwai, Y. \& Ōmura, S. Mode of submerged spore formation in Kitasatosporia setae. J. Gen. Appl. Microbiol. 37, 261-266 (1991).

17 Carvajal, F. The production of spores in submerged cultures by some. Streptomyces Mycol. 39, 4262-4440 (1947).

18 Daza, A., Marti, J. F., Dominguez, A. \& Gil, J. A. Sporulation of several species of Streptomyces in submerged cultures after nutritional down shift. J. Gen. Microbiol. 135, 2483-2491 (1989).

19 Glazebrook, M. A., Doull, J. L., Stuttard, C. \& Vining, L. C. Sporulation of Streptomyces venezuelae in submerged cultures. J. Gen. Microbiol. 136, 581-588 (1990).

20 Huber, F. M., Pieper, R. L. \& Mertz, F. P. Sporulation of Streptomyces roseosporus in submerged culture. J. Ind. Microbiol. 2, 235-241 (1987).

21 Kendrick, K. \& Ensign, J. C. Sporulation of Streptomyces griseus in submerged culture. J. Bacteriol. 155, 357-366 (1983).

22 Ochi, K. Metabolic initiation of differentiation and secondary metabolism by Streptomyces griseus: significance of the stringent response (ppGpp) and GTP content in relation to A factor. J. Bacteriol. 169, 3608-3616 (1987).

23 Ochi, K. Changes in nucleotide pools during sporulation of Streptomyces griseus in submerged culture. J. Gen. Microbiol. 133, 2787-2795 (1987).

24 Takahashi, Y., Iwai, Y. \& Omura, S. Physiological regulation of sporulation of Kitasatosporia setae in submerged culture. Actinomycetologica 10, $43-49$ (1996).

25 Stastna, J., Kvapil, P., Caslavska, J. \& Ensign, J. C. Microcycle sporogenesis in some Streptomycetes without shift down treatment. Arch. Microbiol. 156, 263-265 (1991).

26 Ōmura, S. et al. Phosalacine, a new herbicidal antibiotic containing phosphinothricin. Fermentation, isolation, biological activity and mechanism of action. J. Antibiot. 37 829-835 (1984).

27 Inaoka, Y., Tamaoki, H., Takahashi, S., Enokita, R. \& Okazaki, T. Propioxatins A and B, new enkekhalinase $B$ inhibitors. I. Taxonomy, fermentation, isolation and biological properties. J. Antibiot. 39, 1368-1377 (1986).

28 Tamamura, T. et al. Isolation and characterization of terpentecin, a new antitumor antibiotic. J. Antibiot. 38, 1664-1669 (1985).

29 Peczynska-Czoch, W., Mordarski, M., Kaczmaarek, L. \& Nanka-Namirisli, P. Microbial transformation of azacarbazoles. I. N-methylation of alpha.-,..beta.-, and. gamma.carbolines by Kitasatosporia setae strain. Arch. Immunol. Ther. Exp. 35, 89-95 (1987).

30 Iwami, M. et al. A new immunomodulator, FR-900494: taxonomy, fermentation, isolation, and physico-chemical and biological characteristics. J. Antibiot. 40, 612-622 (1987).
31 Kusakabe, H. \& Isono, K. Taxonomic studies on Kitasatosporia cystarginea sp. nov., which produces a new antifungal antibiotic cystargin. J. Antibiot. 41, 1758-1762 (1988).

32 Oda, K. et al. A novel proteinase inhibitor, tyrostatin, inhibiting some pepstatin-insensitive carboxyl proteinase. Agric. Biol. Chem. 53, 405-415 (1989).

33 Maeda, M., Kodama, T., Iwasawa, N., Higuchi, N. \& Amano, N. Production of asparatic proteinase inhibitors by Kitasatosporia kyotoensis. Eur. Patent Appl. 0316907, A2 (1989).

34 Sawada, H., Motoike, M., Kodo, S., Watanabe, T. \& Kuroda, A. Manufacture of phospholipase D with Kitasatosporia SK-60. Japanese Patent, Jpn. Kokai Tokkyo Koho, 1989-0808285 (1989).

35 Taguchi, R. et al. (1989) Agrochemical F-0368 manufacture with Kitasatosporia. Jpn. Kokai Tokkyo Koho, 1989-231892 (1989).

36 Yeo, W. H., Kim, S. K. S., Kim, S., Yu, S. H. \& Park, E. K. Taxonomy and fermentation of Kitasatosporia kimorexae producing new thiopeptide antibiotics, kimorexins. J. Microbiol. Biotech. 4, 354-359 (1994).

37 Chung, Y. R. et al. Kitasatospora cheerisanensis sp. nov., a new species of the genus Kitasatospora that produces an antifungal agent. Int. J. Syst. Bacteriol. 49, 753-758 (1999).

38 Caruso, M. et al. Studies on a strain of Kitasatospora sp. paclitaxel producer. Ann. Microbiol. 50, 89-102 (2000).

39 Aroonsri, A. et al. Pleiotropic control of secondary metabolism and morphological development by $\mathrm{KsbC}$, a butyrolactone autoregulator receptor homologue in Kitasatospora setae. Appl. Environ. Microbiol. 78, 8015-8024 (2012).

40 Arens, J. C., Berrue, F., Peason, J. K. \& Ken, R. G. Isolation and structure elucidation of satosporin A and B: new polyketides from Kitasatospora griseola. Org. Lett. 15, 3864-3867 (2013).

41 Heine, D., Martin, K \& Hertweck, C. Genetics-guided discovery of endophenazines from Kitasatospora sp. HKI 714. J. Nat. Prod. 77, 1083-1087 (2014).

$42 \mathrm{Wu}$, C., Wezel, G. P. \& Choi, H. Identification of novel endophenaside antibiotics produced by Kitasatospora sp. MBT66. J. Antibiot. 68, 445-452 (2015).

43 Ichikawa, N. et al. Genome sequence of Kitasatospora setae NBRC 14216 ${ }^{\top}$ : an evolutionary snapshot of the family Streptomycetaceae. DNA Res. 17, 393-406 (2010).

44 Arens, J. C., Haltli, B. \& Ken, R. G. Draft genome sequence of Kitasatospora griseora strain MF730-N6, a Bafilomycin, Terpentecin, and Satosporin producer. Genome Announc. 3, e00208-e00215 (2015).

45 Genevieve, G. et al. Analysis of novel Kitasatospora reveals significant evolutionary changes in conserved developmental genes between Kitasatospora and Streptomyces. Antonie Van Leeuwenhoek 106, 365-380 (2014).

46 Hwang, J. Y. et al. Analysis of a draft genome sequence of Kitasatospora cheerisanensis KCTC 2395 producing bafilomycin antibiotics. J. Microbiol. 53, 83-89 (2015). 